\title{
Comparative Performance of Corymbia Hybrids and Parental Species in Subtropical Queensland and Implications for Breeding and Deployment
}

\author{
By D. J. LeE ${ }^{\left.1), 2),{ }^{*}\right)}$, J. R. Huth ${ }^{1)}$, J. T. BrawneR ${ }^{3)}$ and G. R. Dickinson ${ }^{2), 4)}$
}

(Received 25 $5^{\text {th }}$ March 2008)

\begin{abstract}
Eighty six full-sib Corymbia $\mathrm{F}_{1}$ hybrid families (crosses between $C$. torelliana and four spotted gum taxa: C. citriodora subsp. variegata, C. citriodora subsp. citriodora, $C$. henryi and C. maculata), were planted in six trials across six disparate sites in south-eastern Queensland to evaluate their productivity and determine their potential utility for plantation forestry. In each trial, the best-growing $20 \%$ of hybrid families grew significantly faster $(P=0.05)$ than open-pollinated seedlots of the parent species Corymbia citriodora subsp. variegata, ranging from $107 \%$ to $181 \%$ and $127 \%$ to $287 \%$ of the height and diameter respectively. Relative performance of hybrid families growing on more than one site displayed consistency in ranking for growth across sites and analysis showed low genotype-by-environment interaction.
\end{abstract}

Heritability estimates based on female and male parents across two sites at age six years for height and diameter at breast height, were high $(0.62 \pm 0.28$ to $0.64 \pm 0.35$ and $0.31 \pm 0.21$ to $0.69 \pm 0.37$ respectively), and low to moderate $(0.03 \pm 0.04$ to $0.33 \pm 0.22)$ for stem straightness, branch size, incidence of ramicorns, and frost and disease resistance traits at ages one to three years. The proportion of dominance variance for height and diameter had reduced to zero by age six years.

Based on these promising results, further breeding and pilot-scale family forestry and clonal forestry deployment is being undertaken. These results have also provided insights regarding the choice of a future hybrid breeding strategy.

Key words: Spotted gums, Hybrid, Corymbia, Eucalypt, Quambalaria, Breeding strategy, Deployment, Heritability, Genetic parameters.

\section{Introduction}

Manipulated eucalypt hybrids have been used in plantation programs in tropical and subtropical regions for the last three decades (VENKATESH and SHARMA, 1977; GRIFFIN, 1988; MARTIN, 1989). The principal reasons why inter-specific hybrids are exploited for plantations are to allow expansion of plantations onto areas that are marginal for the pure parental species, to combine

\footnotetext{
1) Queensland Primary Industries and Fisheries, Locked Bag 16 Fraser Road, Gympie, Queensland, 4570, Australia.

2) Faculty of Science, Health and Education, University of the Sunshine Coast, Maroochydore DC, Queensland, 4558, Australia.

3) CSIRO, 306 Carmody Rd., St Lucia Queensland, 4067, Australia.

4) Queensland Primary Industries and Fisheries, P.O. Box 1054, Mareeba, Queensland, 4880, Australia.

*) Author for correspondence: DAVID LEE. Phone +617-54565759, Fax +617-54302887. E-Mail: dlee@usc.edu.au
}

desired traits from parental species and to exploit heterosis (MARTIN, 1989; NIKLES and GRIFFIN, 1992; VERRYN, 2000). As shown in this paper, some of these attributes of hybrids are likely to be drivers of plantation development with Corymbia hybrids in parts of eastern Australia.

The Department of Primary Industries \& Fisheries, Queensland, initiated a hybrid breeding program in 1999, to evaluate the potential of hybrids between Corymbia torelliana (CT) and four spotted gums: C. citriodora subsp. citriodora (CCC) - lemon-scented gum; C. citriodora subsp. variegata (CCV) - spotted gum; C. henryi $(\mathrm{CH})$ - large-leaved spotted gum; and C. maculata $(\mathrm{CM})$ - southern spotted gum. The distributions of these species/subspecies are described in HILL and JoHnson (1995) and MCDONALD and BEAN 2000.

Interest in these Corymbia hybrids arose because:

- many areas where plantation forestry is developing in eastern Australia are considered marginal for the parental species, however valuable timber is harvested from natural stands in these regions;

- spontaneous hybrids present in trials and amenity plantings are vigorous and healthy when compared to pure species in the same plantings;

- seed production of the spotted gums is generally low and sporadic and vegetative propagation is currently impractical;

- there is little synchrony of flowering in seed orchards of multiple provenances of spotted gums (LEE, 2007) and, indeed, in natural stands in the last 10 years;

- the parental species have many complementary traits e.g. form, wood properties, environmental plasticity and resistance to pests and diseases (e.g. Quambalaria pitereka, DicKINsON et al., 2004) indicating the possibility of combining these;

- the plantation industry is interested in growing Corymbia species and hybrids for both wood-chip (short rotations up to 10 years) and for sawlogs (moderate length rotations up to 25 years); and

- CT was known to be easy to propagate by rooted cuttings (DE AssIs, 2000), whereas the spotted gums are difficult to propagate vegetatively (MCCOMB and WROTH, 1986 and LEE et al., 2005), it therefore seemed likely that vegetative propagation of some hybrids would be practicable.

The early growth potential of Corymbia hybrids has been discussed by LEE (2007). Additional results on growth and survival from six trials are presented in this paper. Further, genetic parameters including additive and non-additive effects, as well as the possible exis- 
tence, extent and magnitude of genotype-by-environment interactions are discussed in relation to their possible implications for development of a hybrid breeding strategy in the future.

\section{Material and Methods}

\section{Hybrid trial establishment and measurements}

The 18 CT trees used as female parents in this study were selected from windbreaks and amenity plantings in south-eastern Queensland primarily on their flowering propensity. The genetic diversity of these trees has been assessed and it appears to be similar to that of a broadly based natural provenance of the species (MCVEY, 2004). Each CT mother tree was crossed with several spotted gums using a systematic mating design which aimed to cross each CT mother tree to four (average 4.2) spotted gums. Although imperfect due to logistical constraints, a circular mating design (WHITE et al., 2007) was attempted as follows: $\mathrm{CT}_{1}$ crossed with $\mathrm{CCV}_{1}$, $\mathrm{CCV}_{2} \mathrm{CCV}_{3}$ and $\mathrm{CCV}_{4} ; \mathrm{CT}_{2}$ crossed with $\mathrm{CCV}_{2}, \mathrm{CCV}_{3}$ $\mathrm{CCV}_{4}$ and $\mathrm{CCV}_{5} ; \mathrm{CT}_{3}$ crossed with $\mathrm{CCV}_{3}, \mathrm{CCV}_{4}, \mathrm{CCV}_{5}$ and $\mathrm{CCV}_{6}$; etc). The 30 spotted gum male parents were phenotypic selections from field plantings and seed orchards, established by the Department of Primary Industries \& Fisheries, Queensland. In addition, one spontaneous putative hybrid in an amenity planting was backcrossed to CCV and produced enough seed to be included in three trials.
Control-pollinated seed was produced using the 'one stop pollination' system (HARBARD et al., 1999) with the modification that the entire inflorescence was bagged instead of covering the style with tubing. Bags were removed seven days after pollination and seed collected approximately three months later. Seed from these crosses was used to establish six progeny trials, over a three-year period in the summer rainfall environments of south-eastern Queensland (latitude $26^{\circ} \mathrm{S}$ ). The Corymbia hybrids under evaluation in these trials are CT crossed with CCC, CH, CCV and CM.

Eighty-six interspecific Corymbia hybrid families (3428 trees) were planted along with parental-species controls across the six trials. These included a commercial bulk and 11 individual open pollinated families of $\mathrm{CCV}$ that were unrelated to the hybrids. In addition, 25 CT families from the same 18 female trees that produced the hybrids (seven control-pollinated and 18 openpollinated CT families) were included as pure species controls. The experimental material was established as randomised incomplete block designs with 19 to 46 hybrid families, plus controls per trial (Table 1) as four replicates of two- to five-tree line plots (the latter depending on seedling availability). The trial sites varied in soil type and quality, rainfall and frost incidence (Table 2).

In trials 1, 2 and 3 all Corymbia hybrid seedlings reaching $30 \mathrm{~cm}$ height and with a bound root mass in pot, were included in the trials. Subsequently, approxi-

Table 1. - Numbers of hybrid and control families (or bulk population) by taxon included in the six Corymbia hybrid progeny trials.

\begin{tabular}{|c|c|c|c|c|c|c|c|}
\hline \multirow{2}{*}{ Taxon } & \multicolumn{6}{|c|}{ Trial } & \multirow{2}{*}{ Total } \\
\hline & 1 & 2 & 3 & 4 & 5 & 6 & \\
\hline CT IT & 4 & 11 & 8 & 19 & 20 & 19 & 25 \\
\hline CCV IT & 0 & 1 & 1 & 10 & 10 & 10 & 11 \\
\hline CCV bulk & 1 & 1 & 1 & 1 & 1 & 1 & 1 \\
\hline $\mathrm{CT} \times \mathrm{CCC}$ & 2 & 4 & 4 & 5 & 6 & 6 & 8 \\
\hline $\mathrm{CT} \times \mathrm{CCV}$ & 16 & 29 & 25 & 24 & 24 & 26 & 57 \\
\hline $\mathrm{CT} \times \mathrm{CH}$ & 1 & 3 & 3 & 5 & 7 & 5 & 10 \\
\hline $\mathrm{CT} \times \mathrm{CM}$ & 0 & 0 & 0 & 6 & 8 & 7 & 10 \\
\hline Hybrid $\times \mathrm{CCV}$ & 0 & 0 & 0 & 1 & 1 & 1 & 1 \\
\hline $\begin{array}{l}\text { Total hybrid } \\
\text { families }\end{array}$ & 19 & 36 & 32 & 41 & 46 & 45 & 86 \\
\hline Total entries & 24 & 49 & 42 & 71 & 77 & 75 & 123 \\
\hline
\end{tabular}

Note IT = individual tree seedlots. The CT controls are open-pollinated and control-pollinated crosses from the $18 \mathrm{CT}$ parents of the hybrids. The CCV IT seedlots are not related to the hybrids; however, they and the CCV bulk (which contained 67+ seed parents) are samples from the best provenance of the species (Woondum).

Table 2. - Summary of site details for the six Corymbia hybrid progeny trials.

\begin{tabular}{|c|c|c|c|c|c|c|c|}
\hline Trial & $\begin{array}{l}\text { Australian soil } \\
\text { classification / } \\
\text { site quality } \\
\text { rank }\end{array}$ & $\begin{array}{l}\text { Latitude } \\
\quad\left({ }^{\circ} \mathrm{S}\right)\end{array}$ & $\begin{array}{l}\text { Longitude } \\
\left({ }^{\circ} \mathrm{E}\right)\end{array}$ & $\begin{array}{l}\text { Mean } \\
\text { annual } \\
\text { rainfall } \\
(\mathrm{mm})\end{array}$ & $\begin{array}{c}\text { Elevation } \\
\text { (m asl) }\end{array}$ & $\begin{array}{c}\text { Average } \\
\text { annual rainfall } \\
\text { during trial } \\
(\mathrm{mm})\end{array}$ & $\begin{array}{l}\text { Frost } \\
\text { risk }\end{array}$ \\
\hline 1 & Red Ferrosol /1 & 26.62 & 151.93 & 775 & 410 & 522 & medium \\
\hline 2 & $\begin{array}{l}\text { Black Dermosol } \\
\text { /2 }\end{array}$ & 26.36 & 152.54 & 1047 & 154 & 806 & high \\
\hline 3 & $\begin{array}{l}\text { Grey Dermosol / } \\
5\end{array}$ & 26.36 & 152.54 & 1047 & 165 & 806 & low \\
\hline 4 & Vertosol / 3 & 26.05 & 152.46 & 913 & 80 & 823 & medium \\
\hline 5 & Red Ferrosol / 4 & 26.22 & 151.70 & 676 & 438 & 478 & medium \\
\hline 6 & Red Ferrosol / 4 & 26.74 & 151.96 & 780 & 461 & 509 & high \\
\hline
\end{tabular}

\$ Subjective assessment based on soil depth and fertility $(1=$ best $)$. 
mately $32 \%$ of these seedlings died or were declared runts by age three. As indicated in PotTs and DungeY (2004) abnormal phenotypes are common in eucalypt interspecific hybrids. With this large number of deaths and runts in the trials planted in 2001, all subsequent sowings of hybrids were screened in the nursery and abnormal seedlings (averaging approximately 25\%) were discarded prior to establishment of the trials. This culling prior to planting was successful and subsequent trials 4,5 and 6 exhibited fewer deaths and runts.

The trials were assessed for height growth at ages one and three (and age six for two trials established in 2001), diameter at breast height over bark (DBH) age three (and age six for two trials established in 2001), straightness (subjective scale at each site where: $1=$ twisted, 2 = poor straightness, 3 = just below average straightness, 4 = just above average straightness, $5=$ good straightness, 6 = excellent straightness), number of ramicorns, number of large branches (over $2 \mathrm{~cm}$ diameter in the $1.3 \mathrm{~m}$ to $5.3 \mathrm{~m}$ section of the stem). Additional opportunistic assessments were undertaken for frost damage (height to the highest living shoot) and damage caused by Quambalaria pitereka to either the crown ( $1=$ no crown damage, $2=1$ to $10 \%$ crown damage, $3=11$ to $25 \%$ crown damage, $4=26$ to $50 \%$ crown damage, $5=51$ to $75 \%$ crown damage and $6=75$ to $100 \%$ crown damaged $)$ and/or leader $(1=$ no damage, $2=$ shoot damaged by disease).

\section{Statistical analysis}

The data from the trials were analysed both within and across all sites to evaluate the performance of the hybrids. Fisher's Protected Least Significant Difference test was used to detect differences between Corymbia hybrids and the parental controls within each site. Data from the CCC, CCV and CT controls were dropped from the analyses when estimating genetic parameters, and genetic correlations between taxa and traits. Prior to commencing analyses, outliers for all measured traits were removed from the data and the data were standardised by replication (mean $=0$, variance $=1$ ). ASReml V2.00 (GILMORE et al., 2006) was used to estimate variance components and genetic merit. The linear family model included fixed effects for site and replication and random effects for incomplete blocks, female and male parents, families, parent by test interactions, family by test interactions, while the remaining interactions were combined with the error for to create a pooled error estimate.

The statistical model used for the across-site analysis was:

$$
\begin{aligned}
\mathrm{y}_{\mathrm{ijklm}}= & \mu+\mathrm{S}_{\mathrm{i}}+\mathrm{R}_{\mathrm{ij}}+\mathrm{B}_{\mathrm{ijk}}+\mathrm{F}_{1}+\mathrm{M}_{\mathrm{m}}+\mathrm{FM}_{\mathrm{lm}} \\
& +\mathrm{SF}_{\mathrm{il}}+\mathrm{SM}_{\mathrm{im}}+\mathrm{SFM}_{\mathrm{ilm}}+\mathrm{E}_{\mathrm{ijklm}}
\end{aligned}
$$

where, $\mu=$ overall mean; $S_{i}$ is the fixed effect of the $i^{\text {th }}$ site; $R_{i j}$ is the fixed effect of the $j^{\text {th }}$ replication within the $\mathrm{i}^{\text {th }}$ site; $\mathrm{B}_{\mathrm{ijk}}$ is the random effect of the $\mathrm{k}^{\text {th }}$ block within the $\mathrm{j}^{\text {th }}$ replication of the $\mathrm{i}^{\text {th }}$ site, $E\left(\mathrm{~B}_{\mathrm{ijk}}\right)=0, \operatorname{Var}\left(\mathrm{B}_{\mathrm{ijk}}\right)=\sigma^{2}{ }_{\mathrm{k}}$; $\mathrm{F}_{1}$ is the random effect of the $\mathrm{l}^{\text {th }}$ female parent, $E\left(\mathrm{~F}_{1}\right)=0$, $\operatorname{Var}\left(\mathrm{F}_{1}\right)=\sigma_{1}^{2} ; \mathrm{M}_{\mathrm{m}}$ is the random effect of the $\mathrm{m}^{\text {th }}$ male parent, $E\left(\mathrm{M}_{\mathrm{m}}\right)=0, \operatorname{Var}\left(\mathrm{M}_{\mathrm{m}}\right)=\sigma_{\mathrm{m}}^{2} ; \mathrm{FM}_{\mathrm{lm}}$ is the random effect of the interaction between the $1^{\text {th }}$ female parent and $\mathrm{m}^{\text {th }}$ male parent, $E\left(\mathrm{FM}_{\mathrm{lm}}\right)=0, \operatorname{Var}\left(\mathrm{FM}_{\mathrm{lm}}\right)=\sigma_{\mathrm{lm}}^{2} ; \mathrm{SF}_{\mathrm{il}}$ is the random effect of the interaction between the $i^{\text {th }}$ site and $1^{\text {th }}$ female parent, $E\left(\mathrm{SF}_{\mathrm{il}}\right)=0, \operatorname{Var}\left(\mathrm{SF}_{\mathrm{il}}\right)=\sigma_{\mathrm{il}}^{2}$; $\mathrm{SM}_{\mathrm{im}}$ is the random of the interaction between the $\mathrm{i}^{\text {th }}$ site and the $\mathrm{m}^{\text {th }}$ male parent, $E\left(\mathrm{SM}_{\mathrm{im}}\right)=0$, $\operatorname{Var}\left(\mathrm{SM}_{\mathrm{im}}\right)=\sigma_{\mathrm{im}}^{2} ; \mathrm{SFM}_{\mathrm{ilm}}$ is the random effect of the interaction between $i^{\text {th }}$ site and the $\operatorname{lm}^{\text {th }}$ family, $E\left(\mathrm{SFM}_{\mathrm{ilm}}\right)=0, \operatorname{Var}\left(\mathrm{SFM}_{\mathrm{ilm}}\right)=\sigma^{2}{ }_{\mathrm{ilm}}$; and $\mathrm{E}_{\mathrm{ijklm}}$ is a site specific pooled error term containing the $1^{\text {th }}$ female parent by $j^{\text {th }}$ replication variance, the $\mathrm{m}^{\text {th }}$ male parent by $\mathrm{j}^{\text {th }}$ replication variance, the between plot variance and the within plot error, $E\left(\mathrm{E}_{\mathrm{ijklm}}\right)=0, \operatorname{Var}\left(\mathrm{E}_{\mathrm{ijklm}}\right)=\sigma_{\mathrm{e}}^{2}$. The across-site analyses assumed homogeneous variances of random effects among all trials, while a separate error term was fitted for each trial (heterogeneous residuals; BALTUNis et al., 2008).

Formulae used to estimate genetic parameters were:

Heritability across sites $h^{2}=4 \sigma^{2}{ }_{1} /\left(\sigma^{2}{ }_{l}+\sigma^{2}{ }_{m}+\sigma^{2}{ }_{l m}+\right.$ $\left.\sigma^{2}{ }_{\mathrm{il}}+\sigma^{2}{ }_{\mathrm{im}}+\sigma_{\mathrm{ilm}}^{2}+\sigma_{\mathrm{k}}^{2}+\sigma_{\mathrm{e}}^{2}\right)$

Dominance $\mathrm{d}^{2}=4 \sigma^{2}{ }_{\mathrm{lm}} /\left(\sigma^{2}{ }_{\mathrm{l}}+\sigma_{\mathrm{m}}^{2}+\sigma^{2}{ }_{\mathrm{lm}}+\sigma_{\mathrm{il}}^{2}+\sigma^{2}{ }_{\mathrm{im}}+\right.$ $\left.\sigma^{2}{ }_{\mathrm{ilm}}+\sigma_{\mathrm{k}}^{2}+\sigma_{\mathrm{e}}^{2}\right)$

Type B genetic correlations $\mathrm{r}_{\mathrm{gB}}=\sigma_{1}^{2} /\left(\sigma^{2}{ }_{1}+\sigma_{\mathrm{le}}^{2}\right)$,

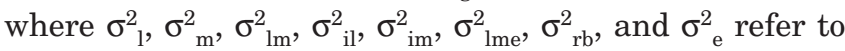
variance component for the female, male, female-bymale interaction, female-by-environment interaction, male-by-environment interaction, female-by-male-byenvironment, block within replication, and error respectively. The error variance was estimated by taking the mean of the site specific errors. Estimates of male and female heritability ( $\mathrm{h}^{2}$ based on spotted gum males versus $C$. torelliana females) and genetic correlations were obtained by substituting $\sigma^{2}$ and $\sigma_{\text {me }}^{2}$ for $\sigma_{1}^{2}$ and $\sigma^{2}$ le in the above equations. Based on taxonomic affinities and the unbalanced representation of each species, homogenous additive variance between the spotted gum fathers was assumed. Approximate standard errors for all terms were calculated in ASReml.

\section{Results and Discussion}

\section{Performance of hybrids and controls}

Average survival of all hybrids including runts, varied from $49.6 \%$ to $82.6 \%$, while the range for CCV controls was $58.0 \%$ to $91.6 \%$ and that for CT was $70.0 \%$ to $94.5 \%$ (Table 3). In trials 1, 2, 3 and 6 the CT individual tree controls had better survival than both the hybrids and the spotted gum species. In trials 1, 2, 4 and 6 the top $20 \%$ of hybrid families with the best growth had similar or better survival than the CCV controls.

In three of the six trials (2,3 and 4) the Corymbia hybrids (including runts) had significantly greater average height growth $(\mathrm{P}=0.05)$ than both the CCV and CT controls. The CCV had similar height growth to the average of the hybrids in trials 1 and 6 and significantly better height growth in trial $5(\mathrm{P}=0.05)$. When the top $20 \%$ best- growth hybrid families at each site were compared to the average of the parental controls they were significantly taller $(\mathrm{P}=0.05)$ than both $\mathrm{CT}$ and $\mathrm{CCV}$. In trial 5 the best $20 \%$ of CCV families were significantly taller than the best $20 \%$ of hybrids families $(\mathrm{P}=0.05)$. At this site, however, the best hybrid family was signifi- 
cantly taller than the best CCV family $(9.2 \mathrm{~m}$ and $8.7 \mathrm{~m}$ respectively; $\mathrm{P}=0.05)$. The $\mathrm{CT}$ controls were significantly shorter than hybrids in all trials $(\mathrm{P}=0.05)$. In trial 2 , CT and CCV had similar height growth and in trial 4, CT was significantly taller than $\mathrm{CCV}(\mathrm{P}=0.05$; Table 3$)$.

Similarly the average DBH of the hybrids was significantly larger than the average of both parental species controls at three sites ( 1 through $3 ; \mathrm{P}=0.05$ ). The average $\mathrm{CCV}$ had a similar $\mathrm{DBH}$ to the hybrids in trial 5; it was however significantly smaller than the hybrids in trial 4 and $6(\mathrm{P}=0.05)$. CT had significantly larger $\mathrm{DBH}$ than CCV $(\mathrm{P}=0.05)$ and similar $\mathrm{DBH}$ to the hybrids in trial 4. It was significantly bigger than CCV in trial 2 $(\mathrm{P}=0.05)$. CT however, is not considered a species with plantation potential in southern Queensland due to its large taper, poor form and branching and relatively poor height growth compared to CCV and the hybrids (LEE, 2007).

In common with many inter-specific hybrid populations (as indicated in the review by POTTS and DUNGEY, 2004), many of the 86 families in these trials were inferior in growth or other important commercial attributes and thus of no practical interest. Rather, it is the betterperforming families that need to be identified and used in further work. When the data for the top $20 \%$ of hybrid families in each trial were averaged, the means of these superior groups ranged from $107 \%$ to $181 \%$ and $127 \%$ to $287 \%$ of the height and $\mathrm{DBH}$ respectively of the CCV average for the trials (based on data in Table 3). In trials 4,5 and 6 , where CCV individual tree seedlots were present, the top $20 \%$ of hybrid families, when compared to the mean to the best two CCV families (20\%), had relative advantages of $93 \%$ to $119 \%$ and $112 \%$ to $151 \%$ for height and DBH respectively. In the same three trials, the best single hybrid family ranged from $115 \%$ to $137 \%$ and $116 \%$ to $170 \%$ the height and $\mathrm{DBH}$ respectively, of the average of the best two CCV families. As CCV individual tree seedlots were not planted in trials 1 to 3, data is not available for a similar comparison in these trials.

The good height (up to $8.6 \mathrm{~m}$ at age three) and $\mathrm{DBH}$ (up to $9.9 \mathrm{~cm}$ at age three) of some of the individual CCV families in trial 5, highlights that some sites may be well suited to this species. Given this, if the sites better suited to CCV could be confidently identified and such better performing spotted gum families could operationally be deployed to them; the need for the Corymbia hybrids might be diminished. However, our inability to identify 'spotted gum sites' and the non-synchronous flowering in spotted gums seed orchards which renders seed supplies totally inadequate, along with our inability to vegetatively propagate spotted gums, means that operational deployment of elite spotted gums families is currently not practical.

Trials 2, 3 and 4 received an average of over $800 \mathrm{~mm}$ per annum of rainfall during the trial period under discussion. It is thought that the growth of both the CCV controls and the hybrid families reflects their potential at these sites. In these three trials the growth of the top $20 \%$ of hybrid families was well in excess of the spotted gums controls at the last measure. The other three trials (1, 5 and 6) received approximately $500 \mathrm{~mm}$ of rainfall per annum during the reported trial period. Given this low rainfall both CCV and the hybrids are growing well; however, both CCV and CT had higher survival across these three sites.

In all the trials the pure spotted gum controls were somewhat damaged by Quambalaria pitereka whereas only a few of the hybrids were observed with symptoms of the disease. As reported earlier (Dickinson et al., 2004), this disease (which causes severe stunting of highly susceptible trees) is thought to be the reason why the spotted gums had higher standard errors for height and DBH than the hybrids in all trials (Table 3 ).

\section{Genetic parameters}

Estimates of the various genetic parameters are documented in Table 4. Heritabilities for height growth increased from near zero at age one to an average for male- and female-parent derived values of 0.62 at age six years. Heritability of DBH also increased strongly from age three to six years. Type B genetic correlations for growth were very high based on male parent and female parents, indicating little genotype-by-environ-

Table 3. - Trial mean survival, height and diameter at breast height over bark \pm standard error of Corymbia hybrids and the parental controls CT and CCV in six trials in south-eastern Queensland (numbers in bracket are means of the top $20 \%$ of families, for that trait, selected by volume growth).

\begin{tabular}{|c|c|c|c|c|c|c|}
\hline \multirow{2}{*}{$\begin{array}{l}\text { Trait } \times \\
\text { taxon }\end{array}$} & \multicolumn{6}{|c|}{ Trial (age) } \\
\hline & 1 (6 year) & 2 (6 year) & 3 (3 year) & 4 (3 year) & 5 (3 year) & 6 (3 year) \\
\hline \multicolumn{7}{|c|}{ Height (m) } \\
\hline CT & $5.7 \pm 0.2$ & $7.7 \pm 0.1$ & $5.0 \pm 0.1$ & $7.1 \pm 0.1$ & $4.2 \pm 0.1$ & $4.1 \pm 0.1$ \\
\hline $\mathrm{CCV}$ & $10.1 \pm 0.5$ & $7.2 \pm 0.2$ & $5.5 \pm 0.2$ & $5.6 \pm 0.2(7.5)$ & $7.1 \pm 0.2(8.2)$ & $5.7 \pm 0.2(6.5)$ \\
\hline Hybrids & $\begin{array}{c}10.1 \pm 0.2 \\
(11.0)\end{array}$ & $\begin{array}{c}10.6 \pm 0.2 \\
(13.0)\end{array}$ & $6.1 \pm 0.1(8.1)$ & $7.3 \pm 0.1(8.9)$ & $6.1 \pm 0.1(7.6)$ & $5.6 \pm 0.1(6.8)$ \\
\hline \multicolumn{7}{|c|}{ Diameter at breast height over bark (cm) } \\
\hline $\mathrm{CT}$ & $7.1 \pm 0.4$ & $8.6 \pm 0.1$ & $6.0 \pm 0.1$ & $8.4 \pm 0.2$ & $6.5 \pm 0.1$ & $4.7 \pm 0.1$ \\
\hline $\mathrm{CCV}$ & $8.6 \pm 0.5$ & $5.8 \pm 0.3$ & $5.2 \pm 0.2$ & $5.0 \pm 0.2(6.4)$ & $8.1 \pm 0.2(9.2)$ & $6.1 \pm 0.2(7.2)$ \\
\hline Hybrids & $\begin{array}{c}10.7 \pm 0.3 \\
(11.9)\end{array}$ & $\begin{array}{c}11.0 \pm 0.1 \\
(13.8)\end{array}$ & $6.8 \pm 0.1(9.9)$ & $7.6 \pm 0.1(9.7)$ & $8.0 \pm 0.1(10.3)$ & $6.7 \pm 0.1(8.9)$ \\
\hline \multicolumn{7}{|c|}{ Survival (\%) } \\
\hline$\overline{C T}$ & 82.4 & 93.2 & 94.5 & 70.0 & 78.5 & 85.0 \\
\hline $\mathrm{CCV}$ & 78.4 & 58.0 & 82.1 & 84.2 & 91.6 & 69.3 \\
\hline Hybrid & $61.3(91.2)$ & $49.6(77.8)$ & $55.3(69.2)$ & $82.6(83.5)$ & $75.3(79.7)$ & $62.0(80)$ \\
\hline
\end{tabular}


Table 4. - Estimates of across-site family heritability $\left(\mathrm{h}^{2}\right)$, genotype-by-environment interaction (Type B genetic correlations, $\left.\mathrm{r}_{\mathrm{gB}}\right)$, the proportion of dominance $\left(\mathrm{d}^{2}\right)$ and the ratio of additive to dominance variance $\left(\sigma_{\mathrm{A}}^{2} / \sigma_{\mathrm{D}}^{2}\right)$ of Corymbia hybrids (CT x spotted gum: CCC, CCV, CH and CM).

\begin{tabular}{|c|c|c|c|c|c|c|c|}
\hline $\begin{array}{l}\text { Trait (No. } \\
\text { trials) }\end{array}$ & $\begin{array}{c}\text { Age } \\
\text { (yrs) }\end{array}$ & $\begin{array}{r}\text { Heritability } \\
\left(\text { female } \mathbf{h}^{2} \text { ) }\right.\end{array}$ & $\begin{array}{c}\text { Heritability } \\
\left(\text { male } \mathrm{h}^{2}\right)\end{array}$ & $\begin{array}{c}\text { Type B } \\
\text { (female } \mathbf{r}_{\mathrm{gB}} \text { ) }\end{array}$ & $\begin{array}{c}\text { Type B } \\
\left.\text { (male } \mathrm{r}_{\mathrm{gB}}\right)\end{array}$ & $\begin{array}{c}\text { Proportion } \\
\text { dominance } \\
\left(\mathrm{d}^{2}\right)\end{array}$ & $\sigma_{A}^{2} / \sigma_{D}^{2}$ \\
\hline Frost (2) & 0.75 & $0.20 \pm 0.22$ & $0.15 \pm 0.18$ & $1.00 \pm 0.00$ & $1.00 \pm 0.00$ & $0.13 \pm 0.26$ & $1.32 \pm 3.22$ \\
\hline Height 1 (5) & 1 & $0.07 \pm 0.07$ & $0.00 \pm 0.00$ & $0.50 \pm 0.00$ & $1.00 \pm 0.00$ & $0.31 \pm 0.08$ & $0.11 \pm 0.12$ \\
\hline Leader (2) & 1 & $0.33 \pm 0.22$ & $0.10 \pm 0.11$ & $1.00 \pm 0.00$ & $1.00 \pm 0.00$ & $0.33 \pm 0.16$ & $0.65 \pm 0.61$ \\
\hline Crown (2) & 1 & $0.00 \pm 0.00$ & $0.14 \pm 0.09$ & $0.86 \pm 0.00$ & $1.00 \pm 0.00$ & $0.16 \pm 0.08$ & $0.43 \pm 0.40$ \\
\hline Height 3 (6) & 3 & $0.07 \pm 0.11$ & $0.49 \pm 0.24$ & $1.00 \pm 0.00$ & $0.97 \pm 0.05$ & $0.53 \pm 0.16$ & $0.52 \pm 0.37$ \\
\hline DBH $3(6)$ & 3 & $0.01 \pm 0.08$ & $0.21 \pm 0.16$ & $1.00 \pm 0.00$ & $0.64 \pm 0.22$ & $0.56 \pm 0.15$ & $0.19 \pm 0.19$ \\
\hline Ramicorns (6) & 3 & $0.04 \pm 0.04$ & $0.03 \pm 0.04$ & $1.00 \pm 0.00$ & $0.32 \pm 0.39$ & $0.12 \pm 0.05$ & $0.26 \pm 0.31$ \\
\hline Branching (6) & 3 & $0.03 \pm 0.04$ & $0.14 \pm 0.09$ & $0.34 \pm 0.33$ & $0.60 \pm 0.21$ & $0.06 \pm 0.05$ & $1.56 \pm 1.89$ \\
\hline Straightness (6) & 3 & $0.19 \pm 0.12$ & $0.32 \pm 0.16$ & $1.00 \pm 0.00$ & $1.00 \pm 0.09$ & $0.30 \pm 0.11$ & $0.86 \pm 0.55$ \\
\hline Height 6 (2) & 6 & $0.62 \pm 0.28$ & $0.64 \pm 0.35$ & $1.00 \pm 0.00$ & $0.83 \pm 0.24$ & $0.00 \pm 0.00$ & na \\
\hline DBH 6 (2) & 6 & $0.31 \pm 0.21$ & $0.69 \pm 0.37$ & $1.00 \pm 0.00$ & $0.86 \pm 0.19$ & $0.00 \pm 0.14$ & na \\
\hline
\end{tabular}

Note: The number of trials assessed for each trait varied due to age and as some traits (e.g. frost and crown and leader damage caused by Quambalaria pitereka) were only observed in a subset of the trials. The ratio of additive to dominance was calculated using the average of the male and female variance estimates of $\sigma_{\mathrm{A}}^{2}$.

ment interactions. Branching and ramicorn traits had very low heritabilities based on both female and male parents.

In the hybrids, CT appears to be contributing more (as reflected by larger additive variances - Table 4) to frost resistance and resistance to attack of the growing shoot (leader) by $Q$. pitereka. Ivory (1998) noted that CT is tolerant of attack by $Q$. pitereka under field conditions. In this study, the hybrids appear to be inheriting this tolerance in an additive manner from both parents. Similarly, CT is reasonably tolerant of frost (LEE, 2007) and appears to be contributing more to the expression of this trait in the hybrids than does the spotted gums. In contrast, the spotted gums appear to be contributing more to the form of the hybrids than the CT; however, the hybrids can benefit by selection for straightness in both parents. Several of the traits (height at age one year, crown, ramicorns and branching) do not appear to make any significant contribution to understanding the hybrid performance or assist with selection of parents for the hybrids.

In the across site analyses, dominance tended to be higher for early growth traits (up to age three), ramicorns and traits associated with disease resistance (leader and crown). By age six years, dominance variance for the growth traits (height and DBH) could not be detected. In this analysis given the good growth performance of the hybrids it was expected that estimates of dominance would be higher. Reasons for this are unknown, but may be related to the small number of female and male parents.

These trials have provided promising initial indications of the potential of the Corymbia hybrids; however, the current trial network generating the information needs expanding in space, number of parents (both within and between species) and time. Given these caveats, the six trials comprising some 86 hybrid fami- lies included in the progeny trials planted in 2001 and 2003 have enabled the rather precise estimation of genetic parameters including genotype-by-environment interactions, additive and additive-to-dominance variance ratios for growth, form and pest and disease resistance - see the generally low standard errors in Table 4. The hybrids are stable in performance across sites, with only traits that had low heritability (branching and ramicorns) showing interactions with sites (Table 4).

For most traits, except frost resistance and leader damage resistance, the proportion of male additive variance is greater than that of the female. It is hypothesised that the relatively narrow genetic base of the CT parents (equivalent to a broadly based provenance; MCVEy, 2004) and the low selection intensity of these trees when compared to the large genetic base from which the spotted gum male parents were selected (different species/subspecies/provenances) may explain the observed different contributions to the additive genetic variance from the male and female parents. When a broader genetic base of CT (e.g. several provenances) is used in the breeding program this issue will be re-examined. Further, when the taxonomic identity of the male parent (CCC, CCV, CH and CM) was included in the linear model as a fixed effect, it was shown to be insignificant. As it did not explain any of the variance and it was therefore excluded from further analyses. This is in line with recent molecular studies indicating that the northern spotted gums (CCC, $\mathrm{CCV}$ and $\mathrm{CH}$ ) could be considered a single species (KING, 2004; OCHIENG et al., 2008; SHEPHERD et al., 2008). Again when hybrids derived from a broader genetic base of spotted gum species/subspecies are available this will be re-examined.

The high heritabilities and ratios of additive to dominance variance of growth traits (height and $\mathrm{DBH}$ ) at age six years clearly show that these traits are under strong additive control. This is in line with results from other 
hybrid tree improvement programs where the parental species are in the first or early cycles of selection (E. urophylla $\times$ E. grandis - BOUVET and Vigneron, 1996; E. urophylla x E. pellita - VIGNERON et al., 2000; $E$. nitens $\times$ E. globulus - VolkER, 1995; and pine hybrids Pinus caribaea var. hondurensis $\times$ P. oocarpa and P. tecunumanii - DiETERs et al., 1997). The additive genetic variances are also increasing with age as was the case with $E$. urophylla $\times E$. grandis in the Congo (VIGNERON et al., 2000).

\section{Possible implications for hybrid breeding strategy with $C T$ and the spotted gums}

Based on the results reported here, a strategy that aims to utilise the substantial additive genetic variance appears appropriate for Corymbia hybrid breeding. As there was little genotype-by-environment interaction, it also appears that breeding does not need to be regionalised, at least within the bounds of the test environments sampled. Early indications from an additional 12 hybrid progeny trials, planted across a much wider range of latitudes $\left(16^{\circ}\right.$ to $\left.30^{\circ} \mathrm{S}\right)$, are that the same families are performing well across many sites (LEE, 2007). These trials will be assessed and data analysed as they reach appropriate ages, and results reported elsewhere.

Three main strategies have been used or proposed for hybrid breeding:

- RRS (reciprocal recurrent selection) with the parent species advanced via recurrent selection in subpopulations chosen on basis of reciprocal hybrid performance. These subpopulations are periodically crossed to produce $\mathrm{F}_{1} \mathrm{~s}$ e.g. E. grandis $\times$ E. urophylla hybrids in the Congo (BARADAT et al., 1994; Bouvet and Vigneron, 1996). This is a very time and resource consuming strategy needing a large established plantation program to justify its use, a criterion not presently met by the hardwood plantation estate in Queensland.

- RRS-SF (reciprocal recurrent selection - selecting forwards) as suggested by NIKLES and GRIFFIN (1992). This strategy reduces the time needed to complete the breeding cycle by developing the pure-species progeny and hybrid progeny from each breeding population at much the same time instead of waiting for selection of the pure species based on their performance as parents of hybrids. This modification of RRS halves the breeding cycle period. The RRS-SF option may be practical for the spotted gum species however the base population of CT needs expanding.

- SYN (synthetic) which uses advance generation hybrid breeding where the parental species are merged to form new synthetic species. This is suggested for the hybrid pine program in Queensland (BRAWNER et al., 2003). The SYN route would only be appropriate if the pure species were amenable to being merged. Various observation of the Corymbia $\mathrm{F}_{1}$ hybrids do not appear to meet this criterion: aberrant flower morphology (buds do not lose their opercula, styles are malformed, etc) and controlled pollinations between $\mathrm{F}_{1}$ hybrids or $\mathrm{F}_{1}$ hybrids and the parental species have to date generally yielded little viable seed. Further work on the flowering and breeding of these hybrids is underway to determine whether the SYN route is practical (DICKINSON et al., 2007). In one successful hybrid $F_{2}$ family developed by this program, there was segregation for rooting and coppicing traits (SHEPHERD et al., 2007) suggesting that segregation may be an issue if a SYN route is attempted.

SHELBOURNE (2000) suggests none of the breeding strategies suggested above appear entirely satisfactory for hybrids.

Based on simulations using a wide range of genetic variances, KERR et al. (2004) recommend where there are only moderate levels of dominance and pure-hybrid correlations are positive that the SYN or RRS-SF will give the best genetic gain per year. Currently we do not have estimates of pure-hybrid genetic correlations but the present indications are that a RRS-SF strategy may be appropriate for the Corymbia hybrids to take advantage of the substantial additive genetic variance and low to moderate levels of dominance identified in this study.

Across Queensland we have 283 Corymbia hybrid families under test in 18 progeny trials. In addition to the germplasm discussed in this paper, this breeding population includes a larger suite of parents from all of the spotted gum taxa as well as individuals from several provenances of CT. Therefore, we consider this population to be large enough to allow for selection of individuals and families with good growth, form pest and disease resistance and wood properties to meet the future demands for this germplasm from the plantation industry. It will also provide an excellent base for genetic parameter estimates that will be used to guide the longterm development and deployment of Corymbia hybrids. In the mean time we are focussing on developing grafted clone banks and seed orchards of selections from the parental species. This will facilitate further breeding and enable a large operational crossing program to be undertaken to reproduce the top Corymbia hybrid families identified in trials.

As reported by LEE (2007) and TRUEMAN and RICHARDSON (2008), the Corymbia hybrids are amenable to propagation as rooted cuttings (range $64 \%$ to $86 \%$ and $11 \%$ to $67 \%$ for hybrid families respectively) and vegetative propagation also appears possible from stump coppice from three-year-old field selections. Based on the performance documented here, vegetative mass propagation of selected hybrid family seedlots, 'family forestry', using outstanding families identified in these trials is being evaluated. In addition, eight partially-tested clones are now being bulked up for pre-commercial release. These clones and families represent the first pre-commercial release from an eight-year-old breeding program.

\section{Conclusions}

The development of Corymbia hybrids is likely to underpin establishment of a sustainable hardwood plantation sector in Queensland and New South Wales, by providing germplasm with superior early growth rates, pest and disease tolerance, environmental plasticity and similar wood properties compared to the current best alternatives (the spotted gum species). Based on the findings of this study; and the suite of positive additional traits: red shouldered leaf beetle resistance, longicorn 
borer resistance, canopy structure, wood properties reported for the Corymbia hybrids (LEE, 2007); and favourable rooting of CT and hybrids with CCC (DE Assis, 2000), the prospect for of establishing large-scale Corymbia hybrids plantations looks promising. The breeding program is in its infancy: field tests need to be run for several more years to achieve full confidence in the hybrids. Based on preliminary findings from this study, a RRS-SF breeding strategy has been adopted for the Corymbia hybrids. This will be reviewed as additional information from these and additional trials are collected as the trials mature.

\section{Acknowledgements}

We thank many staff at Queensland Primary Industries and Fisheries, in particular: Peter Pomroy, John OostENBRINK, Alan WARD, TONY BuRRIDGE and BRUCE HogG for work in the production, establishment and the documenting of trials of the pure species and hybrid populations. Thanks are given to GARTH NIKLES who encouraged development of the pure species and hybrid breeding programs. The contribution of collaborators at Sunshine Coast University: RHONDA STOKOE and HeLen WALlace and Forestry Plantations Queensland whose assistance and work have underpinned much of this research program are greatly appreciated. We thank GARTH NiKLES and TONY SHELBOURNE for prepublication review of the paper.

\section{References}

Baltunis, B. S., H. X. Wu, H. S. Dungey, T. J. Mullin and J. T. BRAWNER (2008): Comparisons of genetic parameters and clonal value predictions from clonal trials and seedling base population trials of radiata pine, Tree Genetics and Genomes 4: 588-688.

Baradat, P., T. LABbÉ and J.-M. Bouvet (1994): Conception d'index por la sélection réciproque récurrente: aspectes génétiques, statistiques et informatiques. Pages 101-150 in Traitements statistiques des essais de séletion. Stratégies d'amélioration des plantes pérennes. Actes du séminaire de biométrie et génétique quantitative. CIRAD, Montpellier, France.

Bouvet, J. M. and P. Vigneron (1996): Variance structure in Eucalyptus hybrid populations. Silvae Genetica 45: 171-177.

Brawner, J. T., M. J. Dieters and D. G. Nikles (2003): Mid-Rotation performance of Pinus caribaea var. hondurensis hybrids with both $P$. oocarpa and $\mathrm{P}$. tecunumanii: stability of parental performance and potential for incorporation into a multi-species synthetic breed. Forest Genetics 10: 233-240.

DE Assis, T. F. (2000): Production and use of eucalyptus hybrids for industrial purposes, pp. 63-74. In: Hybrid Breeding and Genetics of Forest Trees Proceedings of QFRI/CRC-SPF Symposium edited by H. S. DUNGEY, M. J. Dieters and D. G. NikLes, Department of Primary Industries, Brisbane, Australia.

Dickinson, G., H. M. Wallace, N. I. Kelly and D. J. Lee (2007): Inter-specific Corymbia hybrid research; providing new opportunities for plantation expansion in northern Australia, pp. 1-9 in ANZIF 2007 Growing Forest Values. Institute of Foresters of Australia, Coffs Harbour, Australia.

Dickinson, G. R., D. J. LeE and J. R. HuTH (2004): Early plantation growth and tolerance to Ramularia Shoot
Blight of provenances of the spotted gums taxa on a range of sites in southern Queensland. Australian Forestry 67: 122-130.

Dieters, M. J., D. G. Nikles, P. G. Toon and P. Pomroy (1997): Genetic parameters for $F_{1}$ hybrids of Pinus caribaea var. hondurensiswith both Pinus oocarpa and Pinus tecunumanii. Canadian Journal of Forest Research 27: 1024-1031.

Gardner, R. A. W., K. M. Little and A. ARbuthnot (2007): Wood and fibre productivity of promising new eucalypt species for coastal Zululand, South Africa. Australian Forestry 70: 37-47.

Gilmore, A. R., B. J. Gogel, B. R. Cullis, S. J. Welham and R. Thompson (2006): ASReml User Guide, Release 2.0. VSN International Ltd, Hemel Hempstead, UK.

Griffin, A. R., I. P. Burgess and L. Wolf (1988): Patterns of Natural and Manipulated Hybridisation in the Genus Eucalyptus L'Herit. - a Review. Australian Journal of Botany 36: 41-66.

HARBARD, J. L., A. R. GRIFFin and J. EsPeJo (1999): Mass controlled pollination of Eucalyptus globulus: a practical reality. Canadian Journal of Forest Research 29: 1457-1463.

HiLl, K. D. and L. A. S. Johnson (1995): Systematic Studies in the eucalypts. 7. Revision of the bloodwoods genus Corymbia (Myrtaceae). Telopea 6: 185-504.

IVORY, M. H. (1998): Shoot-blight of spotted gums in Queensland, pp. 389-392. In: Farm Forestry and Vegetation Management. Proceedings of the 1998 Managing and Growing Trees Training Conference, edited by A. Grodecki, Department of Natural Resources and Mines, Brisbane, Australia.

KerR, R. J., M. J. Dieters and B. Tier (2004): Simulation of the comparative gains from four different hybrid tree breeding strategies. Canadian Journal of Forest Research 34: 209-220.

KING, R. L. (2004): Spatial structure and population genetic variation in a Eucalypt species complex. $\mathrm{PhD}$ thesis, Griffith University, Brisbane, Australia.

LEE, D. J. (2007): Achievements in forest tree improvement in Australia and New Zealand 2: Development of Corymbia species and hybrids for plantations in eastern Australia. Australian Forestry 70: 11-16.

Lee, D. J., V. J. Debuse, P. C. Pomroy, K. J. Robson and D. G. NiKLES (2005): Developing genetically adapted tree varieties for marginal areas of northern Australia. A report for the RIRDC/Land \& Water Australia/ FWPRDC Joint Venture Agroforestry Program 04/186, Rural Industries Research and Development Corporation, Barton, Canberra, Australia.

Martin, B. (1989): The benefits of hybridization. How do you breed for them?, pp. 79-92. In: Proceedings of the IUFRO conference on breeding tropical trees: Population structure and genetic improvement strategies in clonal and seedling forestry, editors G. L. GIBSON, A. R. Griffin and A. C. Matheson, IUFRO, Pattaya, Thailand.

MсСомв, J. A. and M. Wroth (1986): Vegetative propagation of Eucalyptus resinifera and E. maculata using coppice cuttings and micropropagation. Australian Forest Research 16: 231-242.

McDonald, M. W. and A. R. BeAn (2000): A new combination in Corymbia 'section Politaria': C. citriodora subsp. variegata (Myrtaceae). Austrobaileya 5: 735-736.

McVey, M. G. (2004): Population Genetics of Corymbia torelliana (Cadagi). Honours thesis. University of the Sunshine Coast, Maroochydore, Australia. 
NikLes, D. G. and A. R. GRIFFin (1992): Breeding hybrids of forest trees: Definitions, theory, some practical examples, and guidelines on strategy with tropical Acacias, pp. 101-109. In: Proceedings of a workshop on: Breeding technologies for tropical Acacias, edited by L. T. CArron and K. M. Aken, ACIAR, Tawau, Sabah, Malaysia.

Ochieng, J., M. Shepherd, P. R. Baverstock, D. G. NikLES, D. J. LEE and R. J. HenRY (2008): Genetic variation within two sympatric spotted gum eucalypts exceeds between taxa variation. Silvae Genetica 57: 249-256.

Potts, B. M. and H. Dungey (2004): Interspecific hybridisation of Eucalyptus: key issues for tree breeders and geneticists. New Forests 27: 115-138.

ShelBourne, C. J. A. (2000): Some insights on hybrids in forest tree improvement, pp. 53-62. In: Hybrid breeding and genetics of forest trees, Proceedings of QFRI/CRCSPF Symposium, editors H. S. DungeY, M. J. DieTERS and D. G. NikLES, Department of Primary Industries, Brisbane, Australia.

Shepherd, M., P. Pomroy, M. Dieters and D. J. Lee (2007): Genetic control of propagation traits in a single Corymbia torelliana $\times$ C. variegata family. Canadian Journal of Forest Research 37: 2563-2574.

Shepherd, M., S. Kasem, G. Ablett, J. Ochieng and A. CRAWFORD (2008): Genetic structuring in the spotted gum complex (genus Corymbia, section Politaria). Australian Systematic Botany 21: 15-25.
Trueman, S. J. and D. M. RichaRdson (2008): Relationships between Indole-3-Butyric Acid, Photoinhibition and Adventitious Rooting of Corymbia torelliana, C. citriodora and $\mathrm{F}_{1}$ Hybrid Cuttings. Tree and Forestry Science and Biotechnology 2: 26-33.

VenKatesh, C. S. and V. K. Sharma (1977): Hybrid vigour in controlled interspecific crosses of Eucalyptus tereticornis $\times$ E. camaldulensis. Silvae Genetica 26: 121-124.

VERRYN, S. D. (2000): Eucalyptus hybrid breeding in South Africa, pp. 191-199. In: Hybrid breeding and genetics of forest trees, Proceedings of QFRI/CRCSPF Symposium, editors H. S. Dungey, M. J. Dieters and D. G. NiKLES, Department of Primary Industries, Brisbane, Australia.

Vigneron, P., J. M. Bouvet, R. Gouma, A. SAya, J. M. Gion and D. VERHAEGEN (2000): Eucalypt hybrids breeding in Congo, pp. 14-26. In: Hybrid breeding and genetics of forest trees, Proceedings of QFRI/CRCSPF Symposium, editors H. S. Dungey, M. J. Dieters and D. G. NikLES, Department of Primary Industries, Brisbane, Australia.

VolKer, P. W. (1995): Evaluation of Eucalyptus nitens x globulus for commercial forestry. Pages 222-225 in B. M. Potts, N. M. G. Borralho, J. B. Reid, R. N. Cromer, W. N. Tibbits and C. A. Raymond, editors. Eucalypt plantations: Improving fibre yield and quality. CRC-IUFRO, Hobart, Australia

White, T. L., W. T. Adams and D. B. Neile (2007.): Forest Genetics. Cabi Publishing Oxfordshire UK.

\title{
Performance and Genetic Parameters of Somatic and Zygotic Progenies of Coastal Douglas-fir at 71/2-Years across Washington and Oregon, USA
}

\author{
By C. A. Dean $\left.{ }^{1),}{ }^{*}\right)$, D. E. Welty ${ }^{1)}$ and G. E. Herold ${ }^{2)}$
}

(Received 23 $3^{\text {rd }}$ May 2008)

\begin{abstract}
Five genetic tests involving 37 somatic clones of coastal Douglas-fir (Pseudotsuga menziesii var. menziesii) were planted March 2000 in Weyerhaeuser plantations across western Washington and Oregon States, USA. Four of the tests are in Longview, Twin Harbors and Vail regions of Washington, and one test is in Springfield, Oregon. Each test is based on single-tree plots with 12 randomized complete-blocks. The 37 coastal Douglas-fir clones were propagated by somatic

1) Present address: Weyerhaeuser Company, PO Box 9777, Federal Way, WA 98063-9777, USA.

$\left.{ }^{2}\right)$ Weyerhaeuser Company, George Staebler Research Center, PO Box 420, Centralia, WA 98531-0420, USA.

*) Corresponding author: Christine A. DeAn. E-Mail: Christine. Dean@Weyerhaeuser.com
\end{abstract}

embryogenesis from four full-sib families. Zygotic seedlings from two of these full-sib families were planted across all five tests to allow comparison between somatic and zygotic trees of the same pedigree. Results are reported for survival, stem height, diameter at breast-height $(\mathrm{DBH})$, volume and stem sinuosity at $71 / 2$ years.

On average the total population of 37 somatic clones had less stem sinuosity, but grew more slowly than zygotic trees across the five tests studied. However, the best $20 \%$ of somatic clones for growth produced $25 \%$ greater stem volume at $7 \frac{1}{2}$-years than the zygotic fullsib families. Height had a clonal heritability of $0.61 \pm 0.09, \mathrm{DBH} 0.64 \pm 0.06$, volume $0.58 \pm 0.08$ and stem sinuosity $0.26 \pm 0.06$. The clonal genetic correlation between height and $\mathrm{DBH}$ at $7 \frac{1}{2}$-years was $0.98 \pm 0.01$, while stem sinuosity was adversely genetically correlated with growth. Clonal performance for 